\title{
Genetic Counseling in Middle School Science Club: A Pilot Study
}

\author{
Allison Hutchinson ${ }^{1,2}$, Elizabeth McMillan ${ }^{3}$, Emily Griese ${ }^{4,5}$, Valerie Bares ${ }^{4}$, Quinn Stein ${ }^{1,2,5}$ and Laurie Daily ${ }^{6}$
}

${ }^{1}$ Sanford Health Imagenetics, Sioux Falls, SD; ${ }^{2}$ Department of Genetic Counseling, Augustana University, Sioux Falls, SD; ${ }^{3}$ Sanford PROMISE Science Exploration, Sanford Research, Sioux Falls, SD; ${ }^{4}$ Center for Health Outcomes and Population Research, Sanford Research, Sioux Falls, SD; ${ }^{5}$ Department of Pediatrics, University of South Dakota, Sanford School of Medicine, Sioux Falls, SD; ${ }^{6}$ Department of Education, Augustana University, Sioux Falls, SD

Keywords: Genetic Counseling, Middle School, Education, Underrepresented Minority (URM), Underrepresented in Genetic Counseling (URGC), Diversity, Recruitment

Publication Date: November 19, 2019

DOl: https://doi.org/10.15695/jstem/v2i1.19

\begin{abstract}
Compared to demographic data from other healthcare professions, genetic counselors (GCs) are more likely to be Caucasian females. Many current underrepresented in genetic counseling (URGC) professionals in the field found genetic counseling later in their careers due in part to their lack of awareness. A pilot study consisting of equal numbers of male and female sixth grade science club students was conducted to explore the impact that direct teaching might have on students' awareness of and interest in genetic counseling. The analysis used the non-parametric Wilcoxon signed rank test due to the ordinal, Likert-scale data. Results derived from a pre- and post-survey of lesson participants indicated a statistically significant increase in students' perceptions of having a role model in a science career. Efforts to reach local middle school students to highlight genetic counseling as a potential career choice, especially by role models, may add to the continued work being done to increase the diversity of future genetic counseling applicant pools.
\end{abstract}

\section{INTRODUCTION}

Numerous reports and papers written on the topic of diversity within the healthcare workforce lead with a similar introductory statement: Even with our best efforts in the last so many years, no noticeable change can be seen in the number of URMs (which can stand for underrepresented minorities or underrepresented in medicine) (Jackson and Gracia, 2014; Valantine and Collins, 2015). A snapshot of diversity within the genetic counseling profession, a field of healthcare providers with expertise in genomic medicine and counseling, has faced a similar conundrum. Despite at least a two-decade-long focus on increasing the number of URMs working as genetic counselors (GCs) (Mittman and Downs, 2008), little progress has been made. The National Society of Genetic Counselors (NSGC) has been surveying its members via the Professional Status Survey (PSS) since 1980 to identify workforce trends related to salary and benefits, professional satisfaction, current employment opportunities, and demographics. In 2018, the PSS garnered a 53\% response rate from all sources, the second largest in survey history (Bucheit, 2018). According to the data gleaned in this report, the genetic counseling demographics continue to lag behind other healthcare professions in terms of diversity. (Table 1).
Traditionally, the URM designation has focused on racial and ethnic categorization (Assocation of American Medical Colleges, 2004), as well as gender (Landivar, 2013). Increasingly, the term URM has expanded to include individuals with disabilities (Drum et al., 2011), members of the LGBTQ community (Pizer et al., 2011), socioeconomically disadvantaged individuals, and even nontraditional students who enter a profession later than the norm (Prunuske et al., 2016). Specific to genetic counseling, underrepresented in genetic counseling (URGC) has been defined as an individual who is not a white, able-bodied, heterosexual female (Majmudar, 2019). In light of the participant population in this particular study, the URGC focus will mainly relate to the low percentage of males in the genetic counseling profession. As we continue to understand issues involving URGCs and work toward improved parity, the profession could consider how to refine the widest possible definition of URGCs, while also contributing to the gap in research looking to address the lack of men in female-dominated careers (Croft et al., 2015).

The rationale for increased diversity in healthcare has historically included such reasons as ensuring optimal access to and management of healthcare services, promoting a 
Table 1. Employed persons by detailed occupation, sex, race, and Hispanic or Latino ethnicity

\begin{tabular}{|c|c|c|c|c|c|}
\hline Profession & $\begin{array}{c}\text { Men } \\
\%\end{array}$ & $\begin{array}{c}\text { African American } \\
\%\end{array}$ & $\begin{array}{c}\text { Asian } \\
\%\end{array}$ & $\begin{array}{c}\text { Hispanic or Latino } \\
\%\end{array}$ & $\begin{array}{c}\text { Total minorities } \\
\%\end{array}$ \\
\hline Clinical laboratory technicians & 24.8 & 18.6 & 8.5 & 12.9 & 40 \\
\hline Social workers & 18.4 & 23.6 & 3.5 & 13.4 & 40.5 \\
\hline Registered nurses & 11.4 & 13.1 & 9.0 & 7.2 & 29.3 \\
\hline Physician assistants & 27.9 & 2.9 & 5.1 & 8.2 & 16.2 \\
\hline Respiratory therapists & 36.2 & 17.3 & 13.9 & 11.6 & 42.8 \\
\hline Occupational therapists & 13.2 & 2.5 & 6.4 & 4.2 & 13.1 \\
\hline Physical therapists & 30.5 & 7.4 & 14.3 & 4.3 & 26 \\
\hline Nurse practitioners & 12.8 & 11.2 & 8.8 & 2.6 & 22.6 \\
\hline Speech language pathologists & 4 & 3.5 & 1.2 & 4.8 & 9.5 \\
\hline Genetic counselors & 4 & 1.1 & 7.5 & 2.1 & 11 \\
\hline
\end{tabular}

Note. Demographic data from genetic counselors is from Bucheit, 2018; demographic data from other health professions is from the Bureau of Labor Force Statistics, 2018.

diverse agenda for medical research, and most importantly, bolstering cultural competence (Cohen et al., 2002). Business-related arguments for a continued focus on recruiting and retaining URMs include expanding the existing talent pool, enhancing team dynamics, and growing an institution's relationships to its clients and customers (O'Brien et al., 2015).

Whether thinking of healthcare as business or medicine, the need to build, nurture, and sustain relationships with clients of diverse backgrounds is fundamental to a GC (Uhlmann et al., 2009). In order to better understand who was entering the field, the Genetic Counseling Career Pathway Model (GCCPM) was proposed in 2005 (Oh and Lewis, 2005). This model describes the process potential genetic counseling graduate school applicants must go through on their path to full employment as GCs. The process is not unlike that of other healthcare professionals, beginning with the pool of potential applicants being narrowed from the general population by those who have an interest and an aptitude in the life sciences and/or psychology and the ability to pursue additional education after high school. The siphoning continues as undergraduate students make choices related to the amount of time, money, and energy they are able to devote to officially applying to graduate programs. Once successfully admitted, genetic counseling students must fulfill the requirements of their respective programs and ultimately graduate. Lastly, upon passing the board exam, these individuals may practice as certified GCs and, depending on the state, may obtain licensure.

This pathway has been a valuable tool for over a decade in evaluating where discrepancies in recruitment efforts as compared to results may be originating. Applicant data, though, suggests that the problems in URGC recruitment may be occurring earlier than originally anticipated by the model. Overall, the number of diverse genetic counseling applicants generally correlates to the number of individuals ultimately matriculating into graduate programs around the country. Specifically, in 2017, only 11 percent of initial applicants were male; additionally, other ethnic/racial demographics did not reflect national demographic averages. These figures do not indicate a leaky pipeline once diverse potential applicants begin working toward admission to genetic counseling graduate school. Instead, the opportunity to enhance the limited applicant pool with URGCs may lie many years earlier, before future candidates ever begin to pursue the requirements for admission.

Career Choice Influences. A variety of career development theories exist to help understand how individuals consider and ultimately settle into certain careers. The career development theory with the largest body of research to support its foundational principles is the social cognitive career theory (SCCT). This framework helps to better understand how people form interests, make choices, and take actions to achieve vocational goals. Individuals bring their unique gender, race, ethnicity, socioeconomic status, and disposition to a learning experience, and these factors contribute to feelings of low or high self-efficacy. These beliefs in one's ability to succeed in a certain area or task influence an individual's beliefs about the outcome of the event. External factors serve as supports or barriers, to either help or hinder such feelings (Lent et al., 1994, 2000). If individuals establish and maintain high self-efficacy along with positive outcome expectations, this may lead to interests becoming goals, which can lead to actions. SCCT asserts career development goals develop as children, adolescents, and adults alike unconsciously eliminate possible career paths based on their perception of attainable goals. In short, career choice is a process. As individuals are exposed to career-related activities, they make career-related choices.

Can this career choice process be influenced? If so, how and when? The answers to these questions remain elusive, but some studies do point to the importance of continuing to ask such questions. A longitudinal study composed of two 
Table 2. Summary of past genetic counseling research pertaining to the lack of URGCs in the field

\begin{tabular}{|c|c|c|}
\hline Author(s) & Year & Participant Data and Survey Findings \\
\hline Oh and Lewis & 2005 & $\begin{array}{l}\text { Sampled } 233 \text { high school and college students and found the following factors: ethnicity, gender, parental education, and interest } \\
\text { in biology, were able to predict students' awareness of genetic counseling. Consideration of genetic counseling as a career could be } \\
\text { predicted by the students' level of education, prior awareness of genetic counseling, and interest in psychology, and research suggests } \\
\text { awareness of genetic counseling prior to university may increase diversity (Oh and Lewis, 2005). }\end{array}$ \\
\hline Lega et al. & 2005 & $\begin{array}{l}\text { Surveyed } 235 \text { genetic counseling students, of which thirteen percent identified as minorities. The top reasons for becoming GCs } \\
\text { included a desire to help others and intellectual stimulation. Most had heard of genetic counseling in classes, and one third had a family } \\
\text { history of genetic disease, possibly indicating that familiarity with genetic disease could be a driving factor of genetic counseling } \\
\text { career interest (Lega et al., 2005). }\end{array}$ \\
\hline Schoonveld et al. & 2007 & $\begin{array}{l}\text { Conducted semi-structured telephone interviews with eight genetic counseling students and seven GCs who identified themselves as } \\
\text { either male or minority. The findings of this study indicated that their introduction to the field of genetic counseling was late and some- } \\
\text { what accidental (Schoonveld et al., 2007). }\end{array}$ \\
\hline Owens et al. & 2009 & $\begin{array}{l}\text { Received input from } 28 \text { high school biology and life science teachers via online surveys. The findings indicated most teachers felt they } \\
\text { presented a career as a GC as an option to their students, they agreed the career complemented their curricular activities, and finally } \\
\text { they thought students were generally interested in the career. One of the biggest barriers included overall lack of time within the course } \\
\text { curriculum to discuss any future career options (Owens et al., 2009). }\end{array}$ \\
\hline Kopesky et al. & 2011 & $\begin{array}{l}\text { Surveyed } 190 \text { undergraduate students in upper division science classes to assess their knowledge and perceptions of genetic counsel- } \\
\text { ing. Females were significantly more interested in genetic counseling as a career. Female predictors of interest included estimated sal- } \\
\text { ary career characteristics, perception of genetic counseling as interpersonal, and whether they had already chosen a career. Of interest, } \\
\text { the participants had fairly accurate perceptions of average salary range but inaccurate perceptions of the profession's male to female } \\
\text { ratio }(36 \% \text { to } 63 \%) \text { (Kopesky et al., 2011). }\end{array}$ \\
\hline Kumaravel et al. & 2011 & $\begin{array}{l}\text { Surveyed } 29 \text { high school counselors serving students in ethnically diverse schools. Eighty-three percent of counselors did not discuss } \\
\text { genetic counseling as a career option with students due to lack of resources and perceived lack of student interest (Kumaravel et al., } \\
\text { 2011). }\end{array}$ \\
\hline Pan et al. & 2016 & $\begin{array}{l}\text { Found that } 25 \text { program directors agreed there was a need to increase the general capacity of the genetic counseling workforce pipeline } \\
\text { and barriers included the need for increased funding, accreditation hurdles, lack of availability of clinical sites and faculty, applicant } \\
\text { pool and physical space limitations (Pan et al., 2016). }\end{array}$ \\
\hline Rogers et al. & 2016 & $\begin{array}{l}\text { Surveyed } 349 \text { undergraduate science advisors and found almost } 90 \% \text { of advisors had heard of genetic counseling and that } 47 \% \text { had } \\
\text { discussed the career option with a student advisee in the past year. Genetic counseling was discussed less than other healthcare careers, } \\
\text { despite having similar work environments and similar training programs with required experience to enter programs. Fifty-three per- } \\
\text { cent of undergraduate advisors never discussed genetic counseling in the past year with even one student (Rogers et al., 2016). }\end{array}$ \\
\hline
\end{tabular}

large British cohorts, one born in 1958 and the other born in 1970, showed that even after controlling for factors such as family social background and general cognitive ability, career aspirations recorded at age 16 predicted mid-30's career attainment. Additionally, adolescents with professional career ambitions at this age were more likely to participate in further education and achieve their professional career goals as adults (Schoon and Polek, 2011). These career ambitions may differ according to demographics. By 6th grade, differences can be found in the career aspirations of girls and boys. Furthermore, despite having middle to upper middle class career aspirations, students in low-income schools, particularly students without a college-educated parent, Latino students, and students in the free and reduced lunch program, lacked the awareness of what educational degrees were necessary to realize their career goals (Perry et al., 2016).

Previous Genetic Counseling Pipeline Research. A plethora of research exists showing that those who might be expected to gravitate toward genetic counseling as a viable career option are not doing so. Past studies on the lack of diversity among GCs have focused on students farther along in the genetic education pipeline, and those who might mentor, advise, or teach such students. (See Table 2 for a summary of the pertinent study findings. See Mittman and Downs (2008) for a detailed overview of diversity initiatives prior to 2005). The studies described in Table 2 demonstrate focus solely on students in late high school or in college and beyond.
An ACT Policy Report indicated almost $80 \%$ of middle and early high school students are already thinking about and exploring their options after high school (Wimberly and Noeth, 2005). Even if every person who interacted with a potential applicant was motivated, felt confident, and had adequate time to accurately describe the profession, this may be too late to affect lasting and systemic change in the genetic counseling applicant pool. Studies in neuroscience have also provided pertinent evidence that the brains of adolescents, age 10-25 years, undergo a period of plasticity in which both active and passive experiences sculpt the developing brain (Steinberg, 2014).

Present Study. The purpose of this study was to gauge the feasibility of presenting genetic counseling as a viable career option to middle school students with the goal of increasing their awareness of and interest in genetic counseling. To do this, a hypothetical genetic counseling experience was designed and implemented to articulate the nuanced world of genetics to middle school students, providing them with an opportunity to participate in some of the roles of a GC.

\section{METHODS}

Participants and Procedures. The participants for this pilot study came from a convenience sample of sixth grade students in an urban center middle school in the upper Midwest, of which $52.2 \%$ of the sixth through eighth grade stu- 
Table 3. 2017-2018 Student Demographic Categories of Middle School and District

\begin{tabular}{lcc}
\hline Description & School (\%) & District (\%) \\
\hline Sex (Male) & 52.2 & 51.8 \\
Race/Ethnicity & & \\
$\quad$ White & 71.4 & 62.9 \\
$\quad$ American Indian & 4.4 & 4.4 \\
Hispanic & 9.5 & 11.0 \\
Black & 7.9 & 12.4 \\
Asian & 2.4 & 3.6 \\
Pacific Islander & 0.4 & 0.1 \\
Two or more Races & 4.0 & 5.5 \\
\hline
\end{tabular}

Note. Demographic data from the pilot school and overall district was obtained via personal communication from Smith, 2018

dents were male and $28.6 \%$ of students identified as nonwhite (Smith, 2018). (See Table 3 for demographic data of the middle school and school district at large.)

The students voluntarily attended a science club hosted twice a month before the start of the school day. There was no cost for students to attend the science club. This interest-based club drew around 30 students per meeting. The format included listening to local science career professionals discuss their careers at the first meeting of the month followed by a field experience to their place of work at the second meeting of the month.

Students were recruited for the study in the same manner they were recruited for the science club. The science club advisors and other teachers encouraged students to attend the club via verbal statements during classes. Advertisements for science club participation were placed in the daily announcements and monthly school newsletter. Once parental consent for the science club and pilot study was obtained, students were sent an email invitation from the advisors to complete the pre-survey hosted on the science club's Google Classroom site. The pre-survey link was live from October 2nd to October 19th, the date of the learning experience. Completing the pre-survey was not a requirement for attending the learning experience. All science club students were welcomed to attend and participate. The first question on the survey asked for student assent.

The genetic counseling lesson centered around a hypothetical case involving the parents of Hermione Granger, a character from the Harry Potter series. They were coming to clinic for a genetics consult due to their concern for their daughter's unique magical abilities. The idea for this experience was adapted from the National Library of Medicine's Harry Potter's World: Renaissance Science, Magic, and Medicine (National Library of Medicine, 2017), which is publicly accessible.

The lesson focused on the steps to becoming a GC and participating in the mock genetic counseling visit. Five main parts of a genetic counseling visit were demonstrated, e.g. building rapport/contracting, taking family history, educating and pretest counseling, interpreting and sharing results with the family, and providing support and resources. At the completion of the 40-minute experience, students were invited through verbal reminders to take the post-survey within two weeks. Approval for this pilot study was obtained from Augustana University's Institutional Review Board (approval \# SP17.12) and from Sanford Health System's IRB (approval \# 00001037). Permission was also granted from the Sioux Falls School District and the participating middle school principal.

Measures. Survey questions were compiled and adapted from three published studies: the Science, Technology, Engineering, and Mathematics Career Interest Survey (STEMCIS) (Kier et al., 2014), the Genetic Knowledge Scale (Fitzgerald-Butt et al., 2016), and the STEM Semantics Survey (Tyler-Wood et al., 2010). For the purpose of this paper, only the results of the STEM-CIS survey are reported.

\section{RESULTS}

Only students who took both the pre- and post- surveys $(n=6)$ were utilized in the analysis. (See Table 4 for participant demographics.) Table 5 shows the mean and standard deviation (mean \pm standard deviation) along with $p$-values for each question. Additionally, the STEM-CIS questions were linked to one aspect of the SCCT. Each question was assumed to follow a five-point Likert scale as: $1=$ Strongly Disagree, $2=$ Disagree, $3=$ Neutral, $4=$ Agree, $5=$ Strongly Agree. The analysis used the non-parametric Wilcoxon signed rank test due to the ordinal, Likert-scale data. Question 9 (I have a role model in a science career.) showed a statistically significant increase in scores $(p=0.0488)$.

Table 4. Summary of Participant Demographic Questions

\begin{tabular}{|c|c|c|c|}
\hline Variable & Category & $\begin{array}{l}\text { Pre-Survey } \\
n(\%)\end{array}$ & $\begin{array}{l}\text { Post-Survey } \\
n(\%)\end{array}$ \\
\hline \multirow[t]{2}{*}{ Sex } & Male & $3(50.0 \%)$ & $3(50.0 \%)$ \\
\hline & Female & $3(50.0 \%)$ & $3(50.0 \%)$ \\
\hline Ethnicity & White & $6(100.0 \%)$ & $6(100.0 \%)$ \\
\hline \multirow{3}{*}{$\begin{array}{l}\text { Highest Education } \\
\text { (Mom) }\end{array}$} & School after college & $2(33.3 \%)$ & $2(33.3 \%)$ \\
\hline & College & $4(66.7 \%)$ & $3(50.0 \%)$ \\
\hline & I don't know & $0(0 \%)$ & $1(16.7 \%)$ \\
\hline \multirow{3}{*}{$\begin{array}{l}\text { Highest Education } \\
\text { (Dad) }\end{array}$} & School after college & $1(16.7 \%)$ & $1(16.7 \%)$ \\
\hline & College & $5(83.3 \%)$ & $4(66.7 \%)$ \\
\hline & I don't know & $0(0 \%)$ & $1(16.7 \%)$ \\
\hline
\end{tabular}

\section{DISCUSSION}

In a study led by Chen et al., emerging themes from semi-structured interviews with 25 novice, experienced, or seasoned male GCs along with eight male genetic counsel- 
Table 5. Mean, Standard Deviation, and p value of STEM-CIS Questions

\begin{tabular}{|c|c|c|c|c|c|}
\hline Item No. & SCCT Aspect & Item & Pre- Survey & Post- Survey & $p$-value \\
\hline 1 & Self-Efficacy & I am able to get good grades in my science class. & $4.67 \pm 0.52$ & $5.00 \pm 0.00$ & 0.1729 \\
\hline 2 & Self-Efficacy & I am able to complete my science homework. & $4.83 \pm 0.41$ & $5.00 \pm 0.00$ & 0.5000 \\
\hline 3 & Personal Goal & I plan to use science in my future career. & $3.83 \pm 1.17$ & $4.00 \pm 0.89$ & 0.5000 \\
\hline 4 & Personal Goal & I will work hard in my science classes. & $5.00 \pm 0.00$ & $5.00 \pm 0.00$ & 1.0000 \\
\hline 5 & Outcome Expectation & If I do well in science classes, it will help me in my future career. & $4.50 \pm 0.55$ & $4.33 \pm 0.82$ & 0.9772 \\
\hline 6 & Outcome Expectation & My parents would like it if I choose a science career. & $3.67 \pm 0.82$ & $3.60 \pm 0.55$ & 0.5000 \\
\hline 7 & Interest in Science & I am interested in careers that use science. & $4.00 \pm 1.26$ & $3.67 \pm 1.21$ & 0.9703 \\
\hline 8 & Interest in Science & I like my science class. & $4.83 \pm 0.41$ & $4.80 \pm 0.45$ & 0.6813 \\
\hline 9 & Contextual Support & I have a role model in a science career. & $2.50 \pm 1.76$ & $3.67 \pm 1.37$ & 0.0488 \\
\hline 10 & Personal Input & I would feel comfortable talking to people who work in science careers. & $4.67 \pm 0.52$ & $4.67 \pm 0.52$ & 0.5793 \\
\hline 11 & Contextual Support & I know of someone in my family who uses science in their career. & $2.67 \pm 1.97$ & $3.00 \pm 2.19$ & 0.5000 \\
\hline
\end{tabular}

ing students revealed a general lack of awareness and subsequent late introduction to the field. This suggests the number of male GCs could be influenced by earlier exposure to the profession (Chen et al., 2017). This pilot study sought to determine the degree to which participation in a single, experiential lesson about the parts of a genetic counseling visit could impact the awareness of and interest in genetic counseling as a viable career option for sixth-grade students in a science club. Despite the small number of students completing both the pre- and post-survey, students' ability to say they had a role model in science increased significantly ( $p=$ 0.0488 ) after the lesson. This pilot study generated findings with promising implications for how the genetic counseling profession might continue to work toward greater diversity.

When success seems attainable, relevant role models have been shown to provide a measure of inspiration through identification, connection, and similarity (Lockwood and Kunda, 1997). Furthermore, sensitivity may exist specifically for individuals who are working toward achieving their ideal self, i.e. who are striving for positive self-efficacy. When this is the case, "a positive role model will serve as a constant reminder of accomplishments that are to be pursued" (Lockwood et al., 2002, p. 862). Other professions in search of greater workforce diversity have also identified the importance of role models. Diverse faculty is among the factors identified in maintaining a diverse nursing student population (Gates, 2018). In a national survey of physician assistant program directors, absence of role models was cited by over $60 \%$ of respondents as a perceived barrier to URM recruitment, more than twice as high as the perceived barrier of the state or area population not being diverse (DiBaise et al., 2015). One of many recommendations given after another SCCT-based data analysis into the lack of gender parity in school psychology was to invite minority graduate students to become active participants, i.e. to become role models, in the recruitment process of various pipeline programs (Bocanegra et al., 2016).

One population of particular significance are adolescents with personal or family histories of genetic conditions.
Many GCs have found the career due to their experiences as clients. About one third of respondents to a 2005 study of 235 genetic counseling students reported family histories of genetic conditions (Lega et al., 2005). Therefore, special attention could be given to engaging adolescents seen in genetics clinics in conversations about their future career plans as they begin to transition from pediatric to adult care.

Three additional action steps emerged as a result of this study for further discussion. First, consideration could be given to allow GCs time in their professional schedules to serve as role models in their communities. It worth noting that certified GCs may use involvement in genetics education outreach to satisfy some of the requirements toward recertification (American Board of Genetic Counseling, Inc, 2014). Second, additional IRB-approved procedures and survey tools for eliciting the pre- and post-event thoughts and feelings of adolescents should be deliberated and developed. Third, genetic counseling training programs should continue to develop their own local strategies for increasing URGCs among their applicant pools. Along these lines, we encourage engaging local middle and high school students, teachers, counselors, and administrators where appropriate.

Limitations. This pilot study is limited by its small sample size, single location, and lack of access to socio-economic data. Furthermore, the design bias toward sixth grade students who already have at least some interest in science, as shown by their willingness to voluntarily attend science club before the start of the school day, could be seen as a limitation. Interestingly, findings suggest a potential strategic advantage toward leveraging positive "peer contagion," a term to describe students' own interests and choices being influenced by the level of interest they perceive in a group of their peers (Hazari et al., 2017).

This one-time, 40-minute experience is limited in its ability to provide a life-long impact on students' future career choices; although, one other theory on career development, the Happenstance Learning Theory, highlights the importance of seemingly random events in the process of choosing 
a career and helps to explain why people choose the career path they do (Krumboltz, 2009). Evidence to support this theory can be found in past diversity research. URMs' introduction to the field of genetic counseling has been found to occur late and to be somewhat accidental (Schoonveld et al., 2007).

Future Research. More research is needed to better understand the impact that direct teaching about genetic counseling may have on the curation of a more diverse workforce within the field. There are no simple answers to the questions of why the field is still dominated by Caucasian females. Overall, however, our finding that a short genetics lesson taught to even a small number of students can have a positive influence in whether young people think they have a role model in a science career is a step in the right direction. The applicability and generalizability of the results will require additional studies that include more student participants, at a variety of different schools and locations. The design and implementation of different lesson topics and formats will also be important. Future research on the success of interventions such as this one, as well as other diversity efforts, will need to be evaluated by the long-term outcomes of future genetic counseling applicant pools.

\section{ASSOCIATED CONTENT}

The student presentation and handout used for this pilot study and mentioned in this manuscript are available by contacting the corresponding author.

\section{AUTHOR INFORMATION Corresponding Author}

Quinn Stein. 2001 S. Summit Ave. Sioux Falls, SD 57197. (605) 274-4729. qstein@augie.edu

\section{Author Contributions}

The manuscript was written through contributions of all authors. All authors have given approval to the final version of the manuscript.

\section{FUNDING SOURCES}

Funds to help support the dissemination of this project were provided by an Institutional Development Award (IDeA) from the National Institute of General Medical Sciences of the National Institutes of Health under grant number 5P20GM121341. The content is solely the responsibility of the authors and does not necessarily represent the official views of the National Institutes of Health.

\section{ETHICAL STATEMENTS}

Informed consent was obtained from all parents in order for their child to be included in the study. Assent from the child was also obtained.

\section{ABBREVIATIONS}

GC: Genetic Counselors. GCCPM: Genetic Counseling Career Pathway Model. IDeA: Institutional Development Award. LGBTQ: Lesbian, Gay, Bisexual, Transgender, Queer. NSGC: National Society of Genetic Counselors. PSS: Professional Status Survey. SCCT: Social Cognitive Career Theory. STEM-CIS: Science, Technology, Engineering, and Mathematics Career Interest Survey. URGC: Underrepresented in Genetic Counseling. URM: Underrepresented Minority or Underrepresented in Medicine.

\section{REFERENCES}

American Board of Genetic Counseling, Inc. (2014). Approved PAC Activities. Retrieved February 6, 2018, from https:// www.abgc.net/ABGC/media/Documents/ABGC-PACTable_2014-Updates.pdf

Assocation of American Medical Colleges. (2004, March 19). Underrepresented in medicine definition. Retrieved February 6, 2018, from https://www.aamc.org/initiatives/urm/

Bocanegra, J., Gubi, A., and Cappaert, K. (2016). Investigation of Social Cognitive Career Theory for minority recruitment in school psychology. American Psychological Association, 31(2), 241-255.

Bucheit. (2018). National Society of Genetic Counselors, Inc. Professional Status Survey 2018. (National Society of Genetic Counselors) Retrieved July 11, 2019, from www.nsgc.org

Bureau of Labor Force Statistics. (2017). Labor force Statistics from the current population survey. Retrieved February 6, 2018, from https://www.bls.gov/cps/cpsaat11.htm

Chen, A., McCarthy Veach, P., Schoonveld, C., and Zierhut, H. (2017). Seekers, finders, settlers, and stumblers: identifying the career paths of males in the genetic counseling profession. Journal of Genetic Counseling, 26(5), 948-962.

Cohen, J., Gabriel, B., and Terrell, C. (2002). The case for diversity in the health care workforce. Health Affairs, 21(5), 90102. Retrieved February 23, 2017

Croft, A., Schmader, T., and Block, K. (2015). An Underexamined Inequality: Cultural and Psychological Barriers to Men's Engagement With Communal Roles. Personality and Social Psychology Review, 19(\$), 343-370.

DiBaise, M., Salisbury, H., Hertelendy, A., and Muma, R. (2015). Strategies and perceived barriers to recruitment of underrepresented minority students in physician assistant programs. Journal of Physician Assistant Education, 26(1), 19-27. 
Drum, C., McClain, M., Horner-Johnson, W., and Taitano, J. (2011). Health Disparities Chart Book on Disability and Racial and Ethnic Status in the United States. University of New Hampshire: Institute on Disability. Retrieved from http://www.hppd.vcu.edu/documents/2012/HealthDisparitiesChartBook_080411.pdf

Fitzgerald-Butt, S., Bodine, A., Fry, K., Ash, J., Zaidi, A., Garg, V., Gerhardt, C.A., and McBride, K. (2016). Measuring genetic knowledge: a brief survey instrument for adolescents and adults. Clinical Genetics, 89(2), 235-243.

Gates, S. (2018). What works in promoting and maintainin diversity in nursing programs. Nursing Forum, 1-7.

Hazari, Z., Potvin, G., Cribbs, J., Godwin, A., Scott, T., and Klotz, L. (2017). Interest in STEM is contagious for students in biology, chemistry, and physics classes. Science Advances, $3,1-7$.

Jackson, C., and Gracia, J. (2014). Addressing health and healthcare disparities: the role of a diverse workforce and the social determinants of health. Public Health Reports, 129(Suppl 2), 57-61.

Kier, M., Blanchard, M., Osborne, J., and Albert, J. (2014). The development of the STEM Career Interest Survey (STEMCIS). Research in Science Education, 44(3), 461-481.

Kopesky, J. W., McCarthy Veach, P., Lian, F., and LeRoy, B. S. (2011). Where are all the males? Gender differences in undergraduates' interests in and perceptions of the genetic counseling profession. Journal of Genetic Counseling, 20(4), 341-354.

Krumboltz, J. (2009). The happenstance learning theory. Journal of Career Assessment, 17(2), 135-54.

Kumaravel, S. N., Tabangin, M. E., Sebera, K. E., and Warren, N. S. (2011). Enriching the genetic counseling recruitment pipeline: a national cross-sectional study of public high school counselors. Journal of Genetic Counseling, 20(6), 559-571.

Landivar, L. (2013). Men in nursing occupations: American community survey highlight report. U.S. Census Bureau.

Lega, M., McCarthy Veach, P., Ward, E., and LeRoy, B. (2005). Who are the next generation of genetic counselors? A survey of students. Journal of Genetic Counseling, 14, 395407.

Lent, R., Brown , S., and Hackett, G. (1994). Toward a unifying social cognitive theory of career and academic interest, choice, and performance. Journal of Vocational Behavior, $45,79-122$.

Lent, R., Brown, S., and Hackett, G. (2000). Contextual supports and barriers to career choice: a social cognitive analysis. Journal of Counseling Psychology, 47(1), 36-49.

Lockwood , P., Jordan, C., and Kunda, Z. (2002). Motivation by positive or negative role models: regulatory focus determines who will best inspire us. Journal of Personality and Social Psychology, 83(4), 854-864.

Lockwood, P., and Kunda, Z. (1997). Superstars and me: predicting the impact of role models on the sense of self. Journal of Personality and Social Psychology, 73, 91-103.

Majmudar, G. (2019). Assessing the Impact of Diversity and Inclusion among Individuals in Genetic Counseling Student Cohorts. GSAS Master's Theses Collection. Retrieved September 27, 2019, from http://bir.brandeis.edu/bitstream/handle/10192/36777/MajmudarThesis2019.pdf? sequence $=5 \&$ is Allowed $=\mathrm{y}$
Means, B., Wang, H., Wei, X., Lynch, S., Peters, V., Young, V., and Allen, C. (2017). Expanding STEM opportunities through inclusive STEM-focused high schools. Science Education, $101,681-715$.

Mittman, H., and Downs, K. (2008). Diversity in genetic counseling: past, present and future. Journal of Genetic Counseling, 17, 310-13.

National Library of Medicine. (2017, August 31). Harry Potter's World: Renaissance science, magic, and medicine. Retrieved April 20, 2017, from https://www.nlm.nih.gov/ exhibition/harrypottersworld/education/lessonplan1.html

O’Brien, K., Schaffer, M., van Ness, E., and van der Lee, R. (2015). How to break the cycle of low workplace diversity: a model for change. PLoS ONE, 10(7).

Oh, T., and Lewis, L. (2005). Consideration of genetic counseling as a career: implications for diversitying the genetic counseling field. Journal of Genetic Counseling, 10(7), 71-81.

Owens, T., Tabangin, M. E., Huether, C. A., Vice Bowling, B. V., and Warren, N. S. (2009). High school biology/life science teachers' presentation of genetic counseling and health care career options in their classrooms. Journal of Genetic Counseling, 18(3), 275-86.

Pan, V., Yashar, B. M., Pothast, R., and Wicklund, C. (2016). Expanding the genetic counseling workforce: program directors' views on increasing the size of genetic counseling graduate programs. Genetics in Medicine, 18(8), 842-849.

Perry, B. L., Martinez, E., Morris, E., Link, T. C., and Leukefeld, C. (2016). Misalignment of career and educational aspirations in middle school: differences across race, ethnicity, and socioeconomic status. Social Sciences (Basel, Switzerland), 5(3).

Perry, B. L., Morris, E. W., Link, T. C., and Leukfeld, C. (2016). From athletes to astrophysicists: gender differences in patterns and predictors of career aspirations in pre-adolescence. Social Sciences (Basel, Switzerland), 5(1).

Pizer, J., Sears, B., Mallory, C., and Hunter, N. (2011). Evidence of persistent and pervasive workplace discrimination against LGBT people: The need for federal legislation prohibiting discrimination and providing for equal employment benefits. Symposium: LGBT Identity and the Law . Los Angeles.

Prunuske, A., Wilson, J., Walls, Marrin, H., and Clarke, B. (2016). Efforts at broadening participation in the sciences: an examination of the mentoring experiences of students from underrepresented groups. CBE-Life Sciences Education, 15 .

Rogers, C., Dixon, S., Doyle, L., and Moesel, A. (2016). Career advising about genetic counseling: a look at the current state of familiarity undergraduate career advisors have with genetic counseling. In (unpublished master's thesis). Baltimore, MD: Unversity of Maryland Baltimore.

Schoon, I., and Polek, E. (2011). Teenage career aspirations and adult career attainment: the role of gender, social background and general cognitive ability. International Journal of Behavioral Development, 35(3), 210-217.

Schoonveld, K., McCarthy Veach, P., and LeRoy, B. (2007). What is it like to be in the minority? Ethnic and gender diversity in the genetic counseling profession. Journal of Genetic Counseling, 16(1), 53-69.

Smith, A. (2018, April 24). personal communication. 
Steinberg, L. (2014). Age of opportunity: lessons from the new science of adolescence. Boston: Houghton Mifflin Harcourt.

Tyler-Wood, T., Knezek, G., and Christensen, R. (2010). Instruments in assessing interest in STEM content and careers. Journal of Technology and Teacher Education, 18(2), 341363.

Uhlmann, W., Schuette, J., and Yashar, B. (2009). A guide to genetic counseling. Hoboken, NJ: John Wiley and Sons, Inc.

Wimberly, G. L., and Noeth, R. J. (2005). College readiness begins in middle school. Iowa City, IA: ACT, Inc. 